\title{
Surveillance of work environment and heat stress assessment using meteorological data
}

\author{
Chuansi Gao ${ }^{1}$ (D) $\cdot$ Kalev Kuklane ${ }^{1} \cdot$ Per-Olof Östergren ${ }^{2} \cdot$ Tord Kjellstrom $^{3,4}$
}

Received: 24 November 2018 / Revised: 27 November 2018 / Accepted: 27 November 2018 / Published online: 4 January 2019

(C) The Author(s) 2019

\begin{abstract}
Health surveillance and workplace surveillance are two related but different aspects of occupational health services. The assessment of heat stress using heat indices and thermal models in connection with meteorological data is an important part of surveillance of workplace heat. The assessment of heat exposure provides the basis for occupational health services. Workers should have health surveillance if the high heat stress cannot be reduced.
\end{abstract}

Keywords Workplace surveillance $\cdot$ Health surveillance $\cdot$ Heatstress assessment $\cdot$ Thermal models and indices $\cdot$ Thermal climate $\cdot$ Heat balance

Dear Editor,

The correspondence article by Chirico and Magnavita (2018) raised an important point. We acknowledge the importance of health surveillance for occupational health services. Health surveillance is neither presented as insignificant nor neglected in our paper (Gao et al. 2018). Our paper focuses on identifying and assessing occupational heat stress using heat exposure and meteorological data. It does not intend to cover all aspects of occupational health services including primary, secondary, and tertiary prevention. However, the more focus on primary prevention, the more effective the prevention will be.

Surveillance of work environment, i.e., assessment of heat stress in this case, provides the basis for occupational health services. If the exposure to an occupational health hazard is reduced to the extent that detrimental health effects do not

Chuansi Gao

Chuansi.Gao@design.lth.se

1 Thermal Environment Laboratory, Division of Ergonomics and Aerosol Technology, Department of Design Sciences, Faculty of Engineering, Lund University, Lund, Sweden

2 Social Medicine and Global Health, Department of Clinical Sciences in Malmö, Lund University, Lund, Sweden

3 Centre for Technology Research and Innovation (CETRI Ltd), Lemesos, Cyprus

4 National Center for Epidemiology and Population Health, Australian National University, Canberra, Australia occur, the health surveillance produces no meaningful information. Health surveillance and workplace surveillance (hazard identification, risk assessment, etc.) are two related but different aspects of occupational health services (WHO 2002).

Our paper is in agreement with the paper by Chirico and Rulli (2015) that examines the problem of thermal conditions with a focus on method of evaluation including technical measurements. We emphasize heat exposure assessment, heat indices, and thermal models in connection with meteorological data.

From a global perspective, the greatest heat hazards for workers occur in low-income tropical countries where health surveillance systems and staff and other resources are not available, except in certain factories. For those workers, reduction of additional future heat problems by mitigating climate change is a key issue for primary prevention; in addition, the recognition of heat stress risk, strategies for reducing the risk, and awareness raising to local communities will guide them to their own primary and secondary prevention.

We agree that workers should have health surveillance if the high heat exposure cannot be reduced. Our paper has not focused on health surveillance issue, but on approaches to avoid high heat exposure. On the other hand, health surveillance to a certain extent is already indirectly discussed in our paper although the exact term is not used, where there is a special section "Individual heat strain monitoring," we indicated the need for medical supervision (ISO 12894 :2001) to consider individual factors including work intensity, vulnerable workers such as those who are not acclimatized to heat, 
unfit, frail, aging workers and workers with chronic diseases and disabilities, and monitoring of individual heat strain responses including thermal physiological and psychological responses. However, according to international standard (ISO 12894 :2001), “detailed arrangements for the medical assessment of workers is the responsibility of the occupational physician or occupational health service with oversight of that group of workers." "It is not proposed that formal tests of heat tolerance are adopted, although a past history of heat illness in an individual may indicate heat intolerance and must be given careful consideration."

Furthermore, for vulnerable groups, a separate review paper on health impacts of workplace heat on persons with existing ill health was published (Kjellstrom and Lemke 2017). In the end of our paper (Gao et al. 2018), we emphasized that appropriate protective strategies also need to be designed for working population with vulnerable individuals whose occupational health and performance are negatively impacted by heat stress.

In many studies on climate and health, only one single factor, i.e., air temperature, is used to report climate impact on health. To meet the need of a more comprehensive approach to human thermal environment interactions (Parsons 2014; NIOSH 2016), it is necessary to complement medical education with specific training in the areas of human thermal physiology, climate factors that affect human body heat exchange, heat balance, thermal sensation, thermal comfort, etc. Heat gain in the body is the primary cause of heat induced illnesses. In human heat balance models, a systematic approach (Parsons 2014; Kuklane and Gao 2017) should be used. Such an approach in connection with climate services has been adopted in two ongoing EU projects: Heat-Shield (https://www.heat-shield.eu/) and ClimApp (http://www.lth. se/climapp/).

In summary, health surveillance is one of the significant aspects of occupational services. The focus of our paper (Gao et al. 2018) is on the surveillance of work environment, identification, and assessment of heat stress using meteorological data.

Open Access This article is distributed under the terms of the Creative Commons Attribution 4.0 International License (http:// creativecommons.org/licenses/by/4.0/), which permits unrestricted use, distribution, and reproduction in any medium, provided you give appropriate credit to the original author(s) and the source, provide a link to the Creative Commons license, and indicate if changes were made.

\section{References}

Chirico F, Rulli G (2015) Strategy and methods for the risk assessment of thermal comfort in the workplace. G Ital Med Lav Ergon 37(4):220 233

Chirico F, Magnavita N (2018) The significant role of health surveillance in the occupational heat stress assessment. Int J Biometeorol https:// doi.org/10.1007/s00484-018-1651-y

Gao C, Kuklane K, Östergren PO, Kjellstrom T (2018) Occupational heat stress assessment and protective strategies in the context of climate change. Int J Biometeorol 62(3):359-371. https://doi.org/10.1007/ s00484-017-1352-y

ISO 12894 (2001) Ergonomics of the thermal environment - medical supervision of individuals exposed to extreme hot or cold environments. International Organisation for Standardisation, Geneva

Kjellstrom T, Lemke B (2017) Systematiska kunskapsöversikter; 11. Health impacts of workplace heat on persons with existing ill health. Arbete och Hälsa 51(8)

Kuklane K, Gao C (2017) Systematiska kunskapsöversikter; 10. Occupational heat stress. Arbete och Hälsa 51(7)

NIOSH (2016) NIOSH criteria for a recommended standard: occupational exposure to heat and hot environments. In: Jacklitsch B, Williams WJ, Musolin K, Coca A, Kim J-H, Turner N (eds) U.S. Department of Health and Human Services, Centers for Disease Control and Prevention, National Institute for Occupational Safety and Health, DHHS (NIOSH) Publication 2016-106, Cincinnati, OH

Parsons K (2014) Human thermal environments: the effects of hot, moderate, and cold environments on human health, comfort, and performance, 3rd edn. CRC Press, London

WHO Regional Office for Europe (2002) Good practice in occupational health services: a contribution to workplace health. WHO Regional Office for Europe, Copenhagen http://www.who.int/iris/handle/ 10665/107448 Accessed 18 Nov 2018 